\title{
The effect of network modelling on harmonic propagation studies in power electronics rich transmission networks
}

\author{
Document Version \\ Accepted author manuscript
}

Link to publication record in Manchester Research Explorer

\section{Citation for published version (APA):}

Zhu, J., Becirovic, E., \& Milanovic, J. V. (2018). The effect of network modelling on harmonic propagation studies in power electronics rich transmission networks. In 11th IET International Conference on Advances in Power System Control, Operation and Management (APSCOM 2018)

\section{Published in:}

11th IET International Conference on Advances in Power System Control, Operation and Management (APSCOM 2018)

\section{Citing this paper}

Please note that where the full-text provided on Manchester Research Explorer is the Author Accepted Manuscript or Proof version this may differ from the final Published version. If citing, it is advised that you check and use the publisher's definitive version.

\section{General rights}

Copyright and moral rights for the publications made accessible in the Research Explorer are retained by the authors and/or other copyright owners and it is a condition of accessing publications that users recognise and abide by the legal requirements associated with these rights.

\section{Takedown policy}

If you believe that this document breaches copyright please refer to the University of Manchester's Takedown Procedures [http://man.ac.uk/04Y6Bo] or contact uml.scholarlycommunications@manchester.ac.uk providing relevant details, so we can investigate your claim.

\section{OPEN ACCESS}




\title{
The Effect of Network Modelling on Harmonic Propagation Studies in Power Electronics Rich Transmission Networks
}

\author{
Jing Zhu ${ }^{1} \quad$ Elvisa Bećirović ${ }^{2} \quad$ Jovica V. Milanović ${ }^{3}$ \\ ${ }^{1}$ State Grid Hangzhou Electric Power Co.,Ltd, Hangzhou, China \\ E-mail: jingzhu125@hotmail.com \\ ${ }^{2,3}$ School of Electrical and Electronic Engineering, The University of Manchester, Manchester, UK \\ E-mail: elvisa.becirovic@manchester.ac.uk, milanovic@ manchester.ac.uk
}

\begin{abstract}
This paper investigates the effect of transmission lines/cables and transformers modelling on harmonic propagation studies in power electronics rich transmission networks. It compares the available models of lines and transformers, and formulates nine case studies by pairing different models. Probabilistic harmonic propagation studies are then carried out considering different harmonic injection by renewable energy sources (wind and PV plants) under different operating conditions. Total harmonic distortion (THD) at critical buses in the network is calculated and the effect of different models of lines and transformers used on recorded 95 percentile of THD at critical buses is assessed. The analysis is carried out on the modified IEEE 68 bus test network.
\end{abstract}

Keywords-harmonics, transmission lines and transformer modelling, uncertainty, Monte Carlo simulations

\section{INTRODUCTION}

The concept of power quality has raised concerns among both electric utilities and end users since it was first put forward in the late 1980 [1]. In recent decades, the increasing penetration of power electronics (PE) in transmission networks, including generation, storage and load technologies, has renewed interest in harmonic studies and harmonic mitigation in particular [2]. In order to assess realistically the network performance and meet the need for harmonic mitigation, an appropriate model of the whole network is required. This model is significant since it helps power system utilities to estimate the harmonics level during operation and address the problem from the perspective of the whole network. At present, network models are usually designed and simulated under the fundamental frequency, which is not suitable for harmonic studies. Over the past years, if not decades, equivalent models of lines/cables and transformers have been presented and validated, which is covered in the following section in detail. The recommendations regarding the application of these models in the network are still lacking. In particular, the combined effect of the models of lines and transformers and the comparison of the results obtained with a range of different models on the same test network has not been studied in sufficient detail.

Therefore, this study focuses on the analysis of the influence of network component modelling, namely transmission lines and transformers, on harmonic propagation studies in $\mathrm{PE}$ rich transmission networks. Following probabilistic harmonic propagation studies considering different harmonic injection by renewable energy sources (wind and PV plants) under different operating/loading conditions total harmonic distortion (THD) at critical buses in the network is calculated and the effect of different models of lines and transformers studied. The 95 percentile of THD at critical buses is calculated and used as a principal index for comparison of the effect of different models on harmonic propagation. The analysis is carried out on the modified IEEE 68 bus test network in DigSILENT/PowerFactory environment.

\section{MODELLING OF LINES AND TRANSFORMERS}

\section{Line/Cable Models}

There are two types of equivalent models for transmission lines/cables: lumped parameter model and distributed parameter model. The lumped model is a simplified version used for its easy implementation and low calculation intensity [3]. The accuracy of the lumped model depends on the product of frequency and length. As reported in [4], the lumped model can be used when the length of the overhead lines is below $240 / h \mathrm{~km}$, while for cables, the limit is $144 / h \mathrm{~km}$, where $h$ is the harmonic order. Once the line length exceeds the limit, the distributed model should be applied.

\section{Model 1: Nominal PI Model}

In the case of the nominal PI model, the lumped series impedance is in the middle of the line, while the shunt admittance is split in half and placed at both ends. It is mainly used to determine the general line parameters and apply load flow analysis $[5,6]$. The circuit diagram of the nominal PI model is shown in Fig. 1.

\section{Model 2: Distributed Parameter Model}

The distributed model is the cascade of infinite small segments and each segment is composed of lumped impedance and admittance, where the parameters are

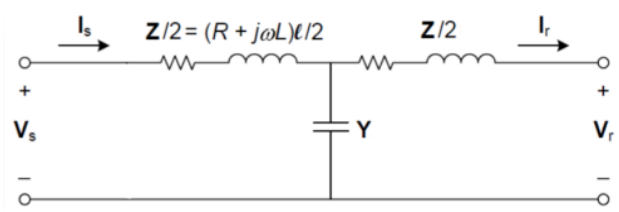

uniformly distributed over the entire line. This model is an accurate representation of the line and suitable for higher order harmonics analysis $[6,7]$. The circuit diagram of the distributed model is shown in Fig. 2.

Fig. 1: Circuit diagram of nominal PI model 


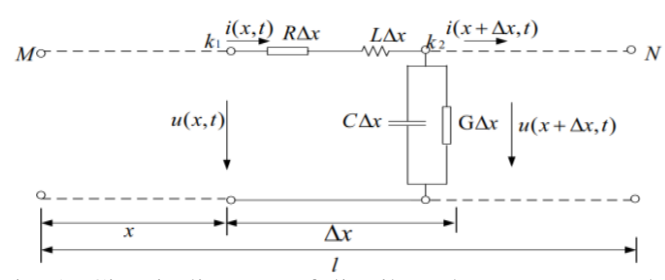

Fig. 2: Circuit diagram of distributed parameter model Modelling Skin Effect of Lines

The skin effect is considered in the nominal line models introduced above. However, the effect becomes prominent in harmonic studies. As reported in, e.g., [8], at high frequencies, the values of resistance and reactance are equal and proportional to the root of frequency. Then the impedance of transmission line considering the effect of harmonics can be modified as

$$
Z(h)=\sqrt{h}(R+j X)
$$

where $Z$ is the series impedance, $R$ and $X$ are the resistance and reactance at the fundamental frequency, and $h$ is the harmonic order.

\section{Transformer Models}

In most situations, it is difficult to gather adequate data for a complete equivalent transformer model. One method is to model using series impedance, which is the case in transformer models used in this research.

Model 1 In the basic transformer model, the resistance is considered as constant and the reactance is proportional to the harmonic order $h$.

$$
Z_{T}(h)=R+j h X
$$

Model 2 The skin effect also exists in transformers and in order to model this characteristic, the series impedance is expressed as [9].

$$
Z_{T}(h)=\sqrt{h} R+j h X
$$

Model 3 Another way to introduce the skin effect into the model, i.e., to put slightly higher emphasis on skin effect, is to set the resistance as proportional to the harmonic order $\mathrm{h}[6]$ instead to $\sqrt{h}$, as in (4).

$$
Z_{T}(h)=\sqrt{h} R+j h X
$$

Model 4 In this model, the DC resistance is used to estimate the resistance under harmonics [10]. The series impedance in this case can be derived as

$$
Z_{T}(h)=R_{0}\left(1+0.1 h^{1.5}\right)+j h X
$$

where $R_{0}$ is the resistance under DC voltage.

\section{TEST SYSTEM AND METHODOLOGY}

In this study, a 16-machine, 68-bus network is adopted as the test system in Digsilent/PowerFactory. It is a simplified equivalent network of the interconnected New England Test System (NETS) and New York Power System (NYPS). As shown in Fig. 3, there are five geographical regions in the system, where NETS and NYPS are equivalent to a group of generators, and each other neighbouring region is represented by a single generator model supplying power to NYPS.

Three harmonic injection sources are considered in the modified (with RES included) IEEE 68-bus test network model: wind turbines (WTs), photovoltaics (PVs) and nonlinear loads. As shown in Table. 1, PVs and WTs use the same magnitude range, while non-linear loads have a different range according to the harmonic spectrum. The individual harmonic phase angles are all assumed to vary from 0 to 180 degrees. The selection of the magnitude and phase angle from the specified range is a random process based on uniform distribution [11]. The harmonic injection in the network from RES and non-linear loads is regarded as a highly stochastic process, thus probabilistic methodology has been used to carry out harmonic propagation studies. Both the generation/load profiles and harmonic injections are modelled using the probabilistic approach. The Monte Carlo simulations considering different probability distribution of injected harmonics by different sources are carried out to represent the one-week operation of the network (16,800 simulations).

The network is initialized by importing RES and load profiles, and then an optimal power flow is performed to determine the participation of conventional generation in the total generation mix. The harmonic injection by different sources is then randomly chosen for each source (100 times per hour) and harmonics power flow executed to calculate THD at all buses in the network.

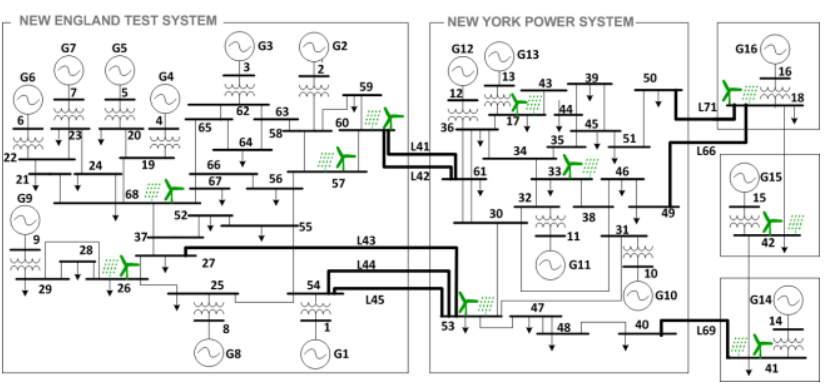

Fig. 3: 68-bus network diagram

Table. 1: Range of harmonic injections [11]

\begin{tabular}{cccc}
\hline Harmonic source & $\begin{array}{c}\text { Harmonic } \\
\text { Order }\end{array}$ & $\begin{array}{c}\text { Magnitude } \\
(\%)\end{array}$ & $\begin{array}{c}\text { Phase } \\
\text { (degree) }\end{array}$ \\
\hline \multirow{3}{*}{ Asynchronous generators } & 5 & $0-0.05$ & $0-180$ \\
(PVs, WTs) & 7 & $0-0.10$ & $0-180$ \\
& 11 & $0-0.15$ & $0-180$ \\
& 13 & $0-0.20$ & $0-180$ \\
Non-linear loads & 5 & $0.01-1.0$ & $0-180$ \\
& 7 & $0.01-1.5$ & $0-180$ \\
& 11 & $0.05-1.0$ & $0-180$ \\
& 13 & $0.03-1.0$ & $0-180$
\end{tabular}

\section{CASE STUdiES}

Based on the individual equivalent models of lines and transformers, nine case studies are formulated and divided into groups, and the results of each case are then presented and compared. In the case of lines, lumped parameter PI model and distributed parameter model are selected for application in Digsilent/PowerFactory, denoted as Model 1 and Model 2, respectively.

Table. 2: List of Study Cases 


\begin{tabular}{|c|c|c|}
\hline Case & Lines & Transformers \\
\hline 1 & $\begin{array}{l}\text { Model } 1 \\
\text { Lumped parameter model }\end{array}$ & $\begin{array}{l}\text { Model } 1 \\
\text { Without skin effect }\end{array}$ \\
\hline & $Z_{L}(h)=R+j h X$ & $Z_{T}(h)=R+j h X$ \\
\hline 2 & $\begin{array}{l}\text { Model } 2 \\
\text { Distributed parameter } \\
\text { model } \\
Z_{L}(h)=R+j h X\end{array}$ & $\begin{array}{l}\text { Model } 1 \\
\text { Without skin effect } \\
Z_{T}(h)=R+j h X\end{array}$ \\
\hline 3 & $\begin{array}{l}\text { Model } 2 \\
\text { Distributed parameter } \\
\text { model } \\
Z_{L}(h)=R+j h X\end{array}$ & $\begin{array}{l}\text { Model } 2 \\
\text { With skin effect } \\
Z_{T}(h)=\sqrt{h} R+j h X\end{array}$ \\
\hline 4 & $\begin{array}{l}\text { Model } 2 \\
\text { Distributed parameter } \\
\text { model } \\
Z_{L}(h)=R+j h X\end{array}$ & $\begin{array}{l}\text { Model } 3 \\
\text { With skin effect } \\
Z_{T}(h)=h R+j h X\end{array}$ \\
\hline 5 & $\begin{array}{l}\text { Model } 2 \\
\text { Distributed parameter } \\
\text { model } \\
Z_{L}(h)=R+j h X\end{array}$ & $\begin{array}{l}\text { Model } 4 \\
\text { With skin effect } \\
Z_{T}(h) \\
=R_{0}\left(1+0.1 h^{1.5}\right)+j h X\end{array}$ \\
\hline 6 & $\begin{array}{l}\text { Model } 3 \\
\text { Distributed parameter } \\
\text { model with skin effect } \\
Z_{L}(h)=\sqrt{h}(R+j X)\end{array}$ & $\begin{array}{l}\text { Model } 1 \\
\text { Without skin effect } \\
Z_{T}(h)=R+j h X\end{array}$ \\
\hline 7 & $\begin{array}{l}\text { Model } 3 \\
\text { Distributed parameter } \\
\text { model with skin effect } \\
Z_{L}(h)=\sqrt{h}(R+j X)\end{array}$ & $\begin{array}{l}\text { Model } 2 \\
\text { With skin effect } \\
Z_{T}(h)=\sqrt{h} R+j h X\end{array}$ \\
\hline 8 & $\begin{array}{l}\text { Model } 3 \\
\text { Distributed parameter } \\
\text { model with skin effect } \\
Z_{L}(h)=\sqrt{h}(R+j X)\end{array}$ & $\begin{array}{l}\text { Model } 3 \\
\text { With skin effect } \\
Z_{T}(h)=h R+j h X\end{array}$ \\
\hline 9 & $\begin{array}{l}\text { Model } 3 \\
\text { Distributed parameter } \\
\text { model with skin effect } \\
Z_{L}(h)=\sqrt{h}(R+j X)\end{array}$ & $\begin{array}{l}\text { Model } 4 \\
\text { With skin effect } \\
Z_{T}(h) \\
=R_{0}\left(1+0.1 h^{1.5}\right)+j h X\end{array}$ \\
\hline
\end{tabular}

The lumped parameter model, however, is not suitable for studies with high order harmonics, thus Model 1 is only adopted in the base case (Case 1) for reference. The distributed parameter model with the skin effect is labelled as Model 3 in the case study. In the case of transformers, there are four models established for comparison. Models 2, 3 and 4 are all considering the skin effect of transformers but different equations are used for describing the skin effect. As shown in Table. 2, by pairing three equivalent line models and four equivalent transformer models, overall nine study cases are set up. The basic impedance equations are provided in the table, and the corresponding model diagrams can be referred to the introduction part.

Calculation of the Risk of exceeding the threshold The term risk of exceeding is defined in IEC standard, where the $95^{\text {th }}$ percentile of THD is set at a limit below $3 \%$ for transmission networks, and it can be expressed as:

\section{Risk of exceeding $=\frac{\text { number of samples higher than } 3 \%(6)}{\text { total number of samples }} \times 100 \%$}

In this 168-hour probabilistic study, the total number of samples is equal to 16,800 . With the data set of 16,800 samples imported, a subroutine in MATLAB is used for plotting the results, and discrete probability density function (PDF) and Burr distribution are chosen to fit the curve. A cumulative density function (CDF) is then derived based on PDF as the risk of exceeding then can be determined and visualized from the plot.

For example, Fig. 4 shows the PDF and CDF plot for the most severe bus, Bus 28 in Case 1, and the probability of samples with THD less than $3 \%$ is $16.7 \%$, thus the risk of exceeding is $100 \%-16.7 \%=83.3 \%$.
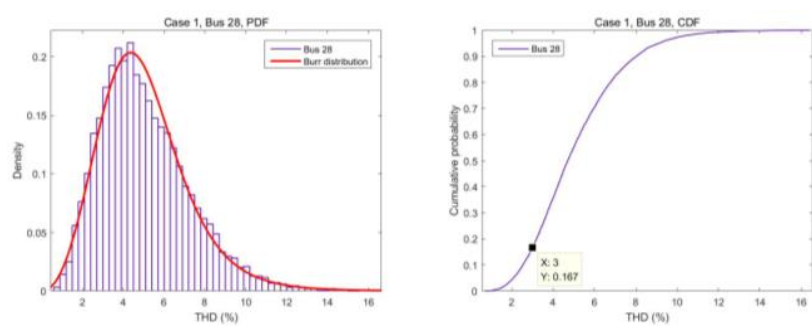

Fig. 4: PDF and CDF plots of THD plot for bus 28 in Case 1

\section{SIMULATION RESULTS AND ANALYSIS}

\section{Case 1 vs Case 2}

The lumped model of lines is used in Case 1, whereas the distributed model is applied in Case 2. Therefore, the effect of these two equivalent models on harmonics propagation can be analysed through the comparison of the results between Case 1 and Case 2. As shown in Fig. 5 and Fig. 6, the overall harmonics level sees a dramatic decrease in Case 2, in particular for the most severe buses in NETS and the buses in the upper part of NYPS, which are circled in red in the diagrams.

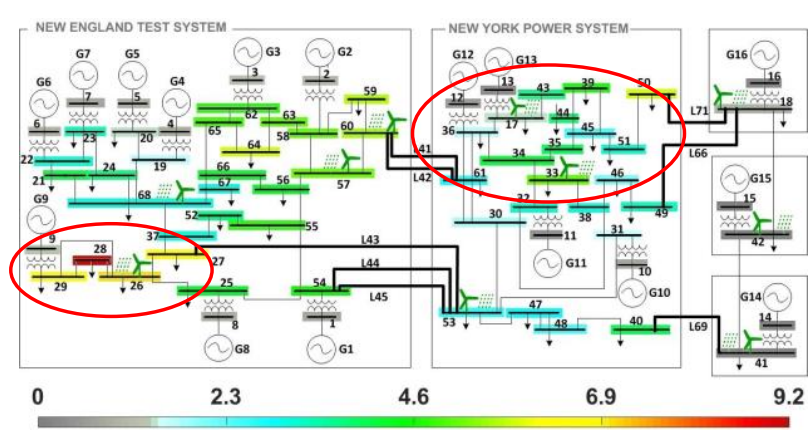

Fig. 5: THD heat map of Case 1

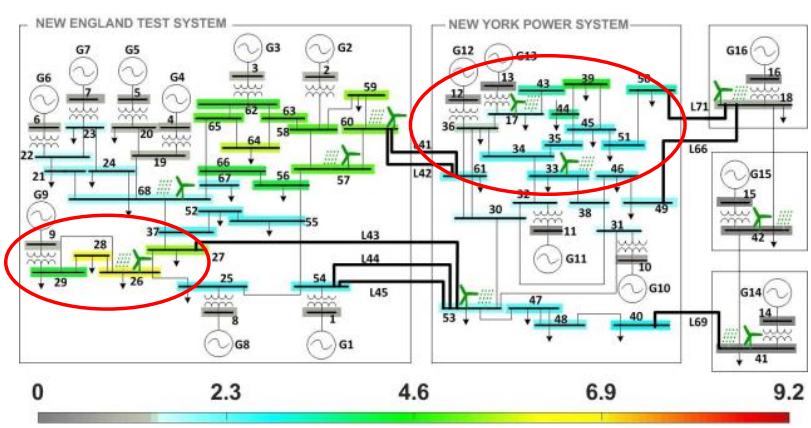

Fig. 6: THD heat map of Case 2 (scale 9.2)

Besides THD, individual harmonic distortion is also studied to gain an insight into the internal mechanism that causes the change. As displayed in Fig. 7 and Fig. 8, the $5^{\text {th }}$ and $7^{\text {th }}$ harmonic have the same distortion level in Case 
1 and Case 2, and a small increase happens in the $13^{\text {th }}$ harmonic distortion, particularly at Bus 39. However, for the $11^{\text {th }}$ harmonic, the distortion drops a lot on most of the buses and all the peak values fall greatly; for example, the value at Bus 28 drops from $7.72 \%$ to $1.92 \%$. Therefore, it can be inferred that the decrease in THD is due to the mitigation/attenuation of the $11^{\text {th }}$ harmonic which also contributed to the change in the worst buses.

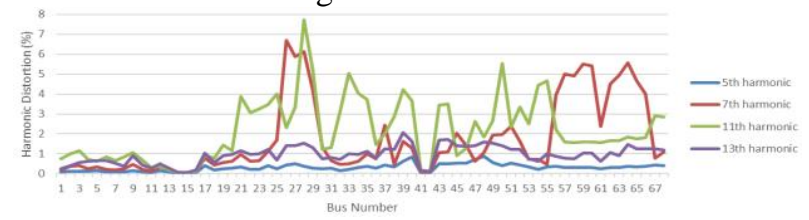

Fig. 7: Individual harmonic distortion at each bus in Case 1

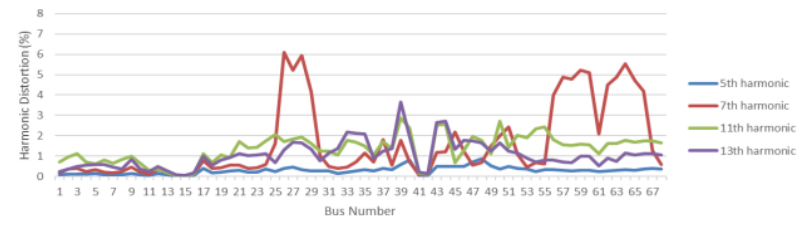

Fig. 8: Individual harmonic distortion at each bus in Case 2

In conclusion, compared to the lumped model, by adopting the distributed model of lines, THD decreases in the whole network, particularly for the worst bus - Bus 28 in Case 1 and Bus 26 in Case 2, for which the reduction in THD reaches $2.86 \%$. For individual harmonics, the $5^{\text {th }}, 7^{\text {th }}$ and $13^{\text {th }}$ harmonic distortion do not change a lot, while the $11^{\text {th }}$ harmonic sees a big drop in distortion when the distributed model is applied.

\section{Case 2 vs Case 6}

Based on the distributed parameter model used in Case 2, the skin effect of the line is introduced and the performance of the two models is compared in Case 6. The heat maps of the two cases are given in Fig. 9 and Fig. 10. (Please note that the heat map of Case 2 in this comparison is different from the one used in the last section as different scaling is used to represent the intensity of THD.) It can be seen that the modelling of skin effect resulted in the increase of the overall distortion level of the network as more 'orange coloured' buses appear in NETS (compare relevant areas of Fig. 10 and Fig. 9), however, the worst buses, 'dark red coloured' buses, disappeared. So the overall distortion level is higher but more uniform without obvious extremes.

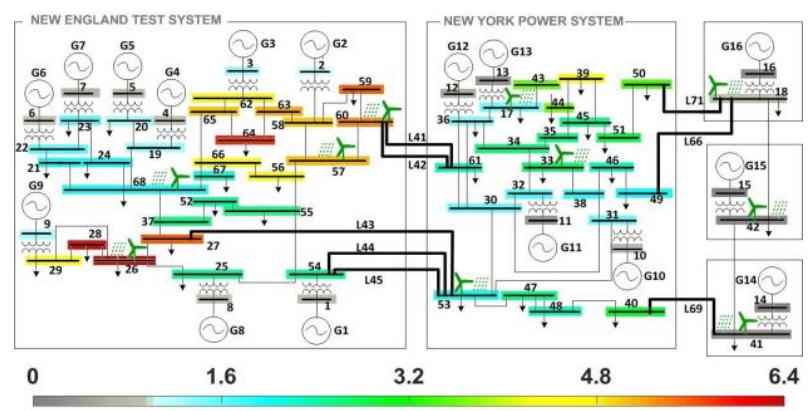

Fig. 9: THD heat map of Case 2 (scale 6.4)

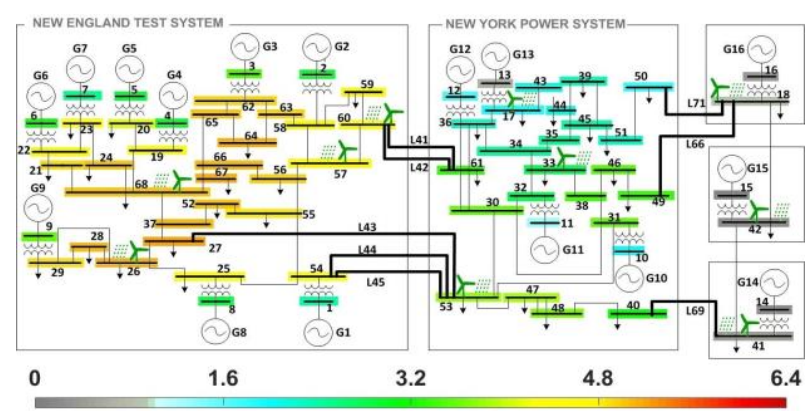

Fig. 10: THD heat map of Case 6

For individual harmonics, Fig. 11 shows distortion at each bus in Case 6 and the results of Case 2 are given by Fig. 8 in the last section. As can be seen from the plot, the $5^{\text {th }}$ harmonic remains at a low level, while the $7^{\text {th }}$ and $11^{\text {th }}$ harmonic drop a lot. More specifically, the peak values of the $11^{\text {th }}$ harmonic decrease to the average level and the curve gets close to the $5^{\text {th }}$ harmonic. The most obvious change happens on the $13^{\text {th }}$ harmonic, where the distortion rises significantly, above $3 \%$ for most of the buses. Therefore, with such a high $13^{\text {th }}$ harmonic component, many buses exceed the limit in Case 6. The reason for the large growth is that harmonic resonance in the network happens around the frequency of the $13^{\text {th }}$ harmonic.

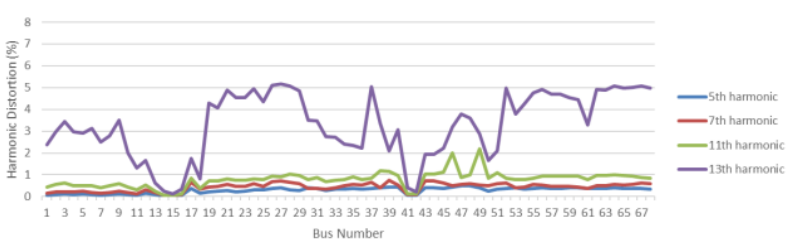

Fig. 11: Individual harmonic distortion at each bus in Case 6

In conclusion, by including the skin effect in the normal distributed parameter line model, the average harmonics level increases in the whole network while the peak THD at some of the critical buses reduces. More specifically, the $5^{\text {th }}$ harmonic distortion remains at a low level, while the $7^{\text {th }}$ and $11^{\text {th }}$ harmonics drop a lot. Since the harmonic resonance of the network is around the frequency of the $13^{\text {th }}$ harmonic, the corresponding distortion is exacerbated.

\section{Case 2 vs Cases 3, 4, 5}

This group of cases is chosen to study the effect of different models of transformers. The transformer model used in Case 2 is for the research at the fundamental frequency, while the models used in Cases 3, 4, 5 include frequency characteristics of resistance, which represents the skin effect of transformers under harmonics.

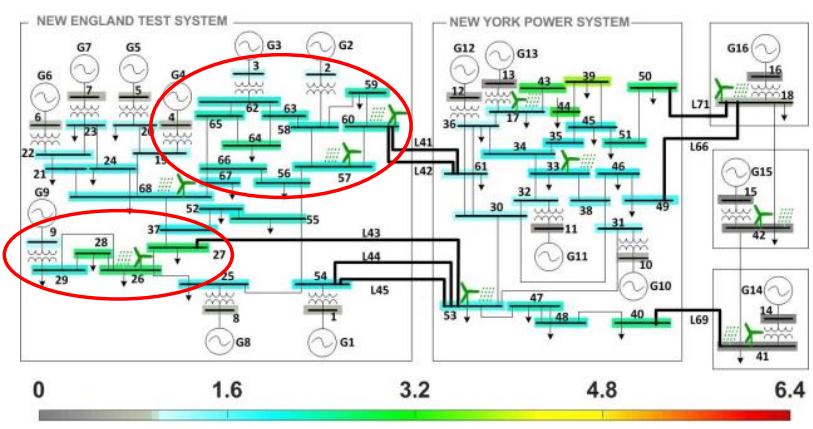

Fig. 12: THD heat map of Case 4

Case 4 shows the best (lowest overall THD in the network) 
performance among Cases 3, 4, 5. Comparing the heat map of Case 2 (Fig. 9) and Case 4 (Fig. 12), the harmonic level is reduced by applying transformer Model 4. As circled in red in the figure, the harmonics in the most severe area of NETS are mitigated to a great extent, even the worst bus is 'green', while the rest of the network stays at a low THD level. Case 3 and Case 5 have a similar harmonic level to that of Case 4, but the reduction is less significant. This behaviour can be explained by the change of multiplying factors. As shown in Table. 2, resistance is multiplied by $\sqrt{h}, h$ and $0.1 h^{1.5}$ for Cases $3,4,5$ respectively, and with a bigger multiplying factor, the resistance gets higher and the mitigation effect becomes more apparent.

\section{Case 1 vs Cases 7, 8, 9}

On the basis of Case 1, the distributed parameter model of the line with the skin effect and the advanced models of transformers with the skin effect included are simultaneously applied in Cases 7, 8, 9. Therefore, the combined effect of line models and transformer models can then be studied by using this group of case studies.

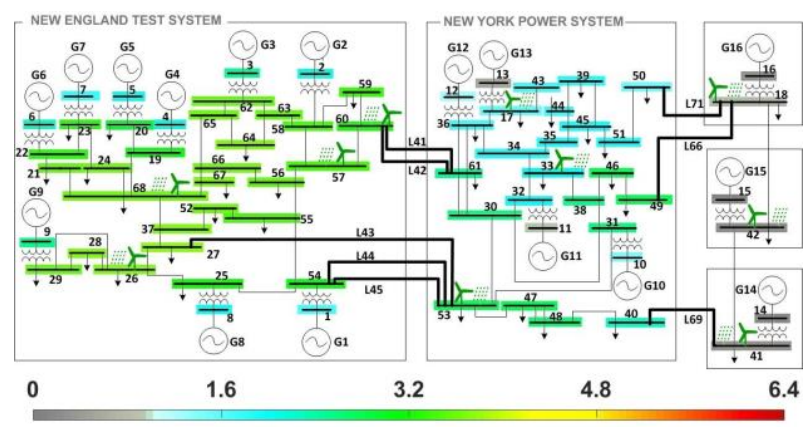

Fig. 13: THD heat map of Case 8

Among these three cases, Case 8 resulted in the best performance (lowest THD), and the overall result is shown in Fig. 13. The THD value is approximately $3.5 \%$ in most regions of NETS and 1.6\%-3.2\% in NYPS. Case 7 and Case 9 have similar features on the distribution of THD, where THD is approximately 5\% in most regions of NETS and $1.6 \%-3.2 \%$ in NYPS. In contrast, the difference of THD in Case 1 is more obvious, as shown in Fig. 5, equally varying from $0 \%$ to $9.2 \%$. Comparing the number of buses exceeding the limit, it is 37 for Case 1 and 39, 26, 37 for Cases 7, 8, 9 respectively. The results show that with skin effect included in the models, the harmonics levels across the network tend to be more uniformly distributed - that is, the harmonic distortion at the most severe buses gets mitigated while the harmonic distortion at the best performing buses deteriorates.

\section{Conclusions from tests}

In addition to the results given for the individual cases, an overview of the whole study is provided in two tables below. As shown in Table. 3, three indices - the number of buses exceeding the limit, the average and the highest THD of 68 buses are used to evaluate the harmonics level. Among all the cases, Case 4 (distributed parameter model for lines and transformer model with skin effect accounted for as $h R$ ) has the best performance as all three indices are the lowest, while Case 1 is regarded as the worst case since the maximum THD is extremely high and the average performance is also poor.

Table. 4 reveals the distribution of the five worst buses in the network. It is evident that Buses 26, 27, 28 and 64 are the worst buses in almost every case. And Bus 39 becomes critical when transformers are modelled using advanced equations (Cases 3, 4, 5). Also Bus 67 appears 4 times in the table after the skin effect of lines is introduced into the model (Cases 7, 8, 9). Therefore, the advanced modelling of the lines and transformers does not significantly change the set of the most critical buses as most of them are fixed with only slight variation in bus criticality (new entries in the set of critical buses) with the change of simulation model.

Table. 3: Overview of harmonics level in each case

\begin{tabular}{cccc}
\hline Case & $\begin{array}{c}\text { Average THD } \\
\text { of } 68 \text { buses (\%) }\end{array}$ & $\begin{array}{c}\text { Highest THD } \\
\text { of } 68 \text { buses (\%) }\end{array}$ & $\begin{array}{c}\text { Number of buses } \\
\text { exceeding the limit }\end{array}$ \\
\hline 1 & 3.00 & 9.11 & 37 \\
2 & 2.40 & 6.25 & 18 \\
3 & 2.00 & 4.26 & 17 \\
4 & 0.79 & 3.81 & 3 \\
5 & 1.96 & 4.16 & 17 \\
6 & 3.36 & 5.23 & 41 \\
7 & 3.20 & 4.97 & 39 \\
8 & 2.46 & 3.75 & 26 \\
9 & 2.96 & 4.58 & 37
\end{tabular}

Table. 4: Five worst buses in each case

\begin{tabular}{cccccccccc}
\hline Case & 1 & 2 & 3 & 4 & 5 & 6 & 7 & 8 & 9 \\
\hline 26 & $\bullet$ & $\bullet$ & $\bullet$ & $\bullet$ & $\bullet$ & $\bullet$ & $\bullet$ & $\bullet$ & $\bullet$ \\
27 & $\bullet$ & $\bullet$ & $\bullet$ & & $\bullet$ & $\bullet$ & $\bullet$ & $\bullet$ & $\bullet$ \\
28 & $\bullet$ & $\bullet$ & $\bullet$ & $\bullet$ & $\bullet$ & $\bullet$ & & $\bullet$ & $\bullet$ \\
29 & $\bullet$ & & & & & & & & \\
37 & & & & & & & $\bullet$ & \\
39 & & & $\bullet$ & $\bullet$ & $\bullet$ & & & \\
43 & & & & $\bullet$ & & & & \\
44 & & & & $\bullet$ & & & & & \\
59 & & $\bullet$ & & & & & & & \\
64 & $\bullet$ & $\bullet$ & $\bullet$ & & $\bullet$ & $\bullet$ & $\bullet$ & $\bullet$ & $\bullet$ \\
67 & & & & & & $\bullet$ & $\bullet$ & $\bullet$ & $\bullet$
\end{tabular}

\section{CONCLUSIONS}

Based on the probabilistic study performed to assess the influence of transformer and line modelling on harmonic propagation studies the following conclusions can be drawn: i) The use of distributed parameter line models results in lower values of calculated THD throughout the network; ii) Modelling the skin effect in lines results in the increase of the average harmonic level in the network though the peak THD drops; iii) Modelling frequency characteristics of transformers has a mitigation effect on harmonic levels; iv) The use of simple models (without skin effect and using lumped parameter model of lines) of lines and transformers typically leads to the overestimated harmonic levels.

\section{Suggestions for Network Modelling}

1) If the aim is to solve the harmonic problem in the network globally, the most severe condition should be 
taken into consideration, which is Case 1. In Case 1, 37 buses see THD above the planning limit level (3\%). Therefore, when modelling the network with the purpose of mitigation, the lumped parameter model $Z_{L}(h)=R+j h X$ of lines and the model $Z_{T}(h)=R+j h X$ of transformers should be adopted.

2) If the aim is to model the harmonic propagation in the system as realistically as possible, the skin effect in lines and transformers has to be included in the model. Then the approach illustrated by Cases 7,8 or 9 should be applied. The cases above use the same model for lines, and various ways to model the skin effect in transformers.

3) It is important to emphasise that the problem of harmonic resonance has to be considered carefully when studying harmonic propagation through the network as the existence of harmonic resonance can significantly affect the propagation studies and the specific influence of harmonic model. It was demonstrated in this study that when the skin effect of lines was modelled, the $13^{\text {th }}$ harmonic was most significantly affected/amplified which was then found to be the resonant harmonic in the network.

\section{ACKNOWLEDGMENT}

This research was partly supported by the EU Horizon 2020 project "MIGRATE" , contract number 691800.

\section{REFERENCES}

[1] R. C. Dugan, M. F. McGranaghan, and H. W. Beaty, "Electrical power systems quality," New York, NY: McGraw-Hill,, c1996, 1996.

[2] M. H. Rashid, Power electronics handbook: devices, circuits and applications: Academic press, 2010.

[3] J. Roldan-Fernandez, F. M. Gonzalez-Longatt, J. L. Rueda, and H. Verdejo, "Modelling of Transmission Systems Under Unsymmetrical Conditions and Contingency Analysis Using DIgSILENT PowerFactory," in PowerFactory Applications for Power System Analysis, ed: Springer, 2014, pp. 27-59.

[4] S. Ranade and W. Xu, "An overview of harmonics modeling and simulation," Tutorial Harmonics Modeling and Simulation, IEEE Power Engineering Society, 1998.

[5] R. Langella, L. Nunges, F. Pilo, G. Pisano, G. Petretto, S. Scalari, et al., "Preliminary analysis of MV cable line models for high frequency harmonic penetration studies," in Power and Energy Society General Meeting, 2011 IEEE, 2011, pp. 1-8.

[6] G. J. Wakileh, Power systems harmonics: fundamentals, analysis and filter design: Springer Science \& Business Media, 2001.

[7] J. Luo, K. Zhang, T. Chen, G. Zhao, P. Wang, and S. Feng, "Distributed parameter circuit model for transmission line," in Advanced Power System Automation and Protection (APAP), 2011 International Conference on, 2011, pp. 15291534.

[8] H. W. Dommel, EMTP theory book: Microtran Power System Analysis Corporation, 1992.

[9] Z. Ma, G. You, and Z. Xu, "Harmonie evaluation of grid with multiple harmonic sources based on DIgSILENT," in Power System Technology (POWERCON), 2014 International Conference on, 2014, pp. 2332-2337.

[10] A. A. Mahmoud and R. D. Shultz, "A method for analyzing harmonic distribution in AC power systems," IEEE Transactions on power apparatus and systems, pp. 1815-
$1824,1982$.

[11] D. Liang, "Harmonic Mitigation In Power Electronics Rich Transmission Networks," The University of Manchester2017. 